\title{
Phylogeny and differentiation of the St genome in Elymus L. sensu lato (Triticeae; Poaceae) based on one nuclear DNA and two chloroplast genes
}

Zhen-Zhen Dong ${ }^{1,2}$, Xing Fan ${ }^{1}$, Li-Na Sha' ${ }^{1}$, Yi Wang ${ }^{1}$, Jian Zeng ${ }^{3}$, Hou-Yang Kang ${ }^{1}$, Hai-Qin Zhang ${ }^{1}$, Xiao-Li Wang ${ }^{4}$, Li Zhang ${ }^{4}$, Chun-Bang Ding ${ }^{4}$, Rui-Wu Yang ${ }^{4}$ and Yong-Hong Zhou ${ }^{1,2^{*}}$

\begin{abstract}
Background: Hybridization and polyploidization can be major mechanisms for plant evolution and speciation. Thus, the process of polyploidization and evolutionary history of polyploids is of widespread interest. The species in Elymus L. sensu lato are allopolyploids that share a common St genome from Pseudoroegneria in different combinations with $\mathrm{H}, \mathrm{Y}, \mathrm{P}$, and W genomes. But how the St genome evolved in the Elymus s. I. during the hybridization and polyploidization events remains unclear. We used nuclear and chloroplast DNA-based phylogenetic analyses to shed some light on this process.

Results: The Maximum likelihood (ML) tree based on nuclear ribosomal internal transcribed spacer region (nrlTS) data showed that the Pseudoroegneria, Hordeum and Agropyron species served as the St, $\mathrm{H}$ and P genome diploid ancestors, respectively, for the Elymus s. I. polyploids. The ML tree for the chloroplast genes (matK and the intergenic region of trnH-psbA) suggests that the Pseudoroegneria served as the maternal donor of the St genome for Elymus s. I. Furthermore, it suggested that Pseudoroegneria species from Central Asia and Europe were more ancient than those from North America. The molecular evolution in the St genome appeared to be non-random following the polyploidy event with a departure from the equilibrium neutral model due to a genetic bottleneck caused by recent polyploidization.

Conclusion: Our results suggest the ancient common maternal ancestral genome in Elymus s. I. is the St genome from Pseudoroegneria. The evolutionary differentiation of the St genome in Elymus s. I. after rise of this group may have multiple causes, including hybridization and polyploidization. They also suggest that E. tangutorum should be treated as $C$. dahurica var. tangutorum, and E. breviaristatus should be transferred into Campeiostachys. We hypothesized that the Elymus s. I. species origined in Central Asia and Europe, then spread to North America. Further study of intraspecific variation may help us evaluate our phylogenetic results in greater detail and with more certainty.
\end{abstract}

Keywords: Elymus s. I., St genome, nr DNA, Chloroplast gene, Phylogeny, Molecular evolution

\section{Background}

Hybridization and polyploidization is a major mechanism in plant evolution and speciation $[1,2]$. Polyploidization by itself has many consequences for genome evolution, particularly for gene expression and gene organization [3-5]. These changes may result in full fertility and stabilization

\footnotetext{
* Correspondence: zhouyh@sicau.edu.cn

${ }^{1}$ Triticeae Research Institute, Sichuan Agricultural University, Wenjiang 611130, Chengdu, Sichuan, China

${ }^{2}$ Key Laboratory of Genetic Resources and Crop Improvement, Ministry of Education, Sichuan Agricultural University, Wenjiang 611130, Chengdu, Sichuan, China

Full list of author information is available at the end of the article
}

of the hybrid condition and assist in establishing the phenotype in nature, which allows polyploids to adapt to new ecological niches or to be competitively superior to the parental donor $[2,6,7]$.

Evolution under polyploidization alone and/or hybridization and polyploidization together can give rise to a complex of lineages whose phylogenetic relationships are unclear. For such groups, molecular genetic analysis is often necessary to elucidate the genome evolution patterns and the phylogenetic relationships among taxa [8].

\section{Biomed Central}

(c) 2015 Dong et al. This is an Open Access article distributed under the terms of the Creative Commons Attribution License (http://creativecommons.org/licenses/by/4.0), which permits unrestricted use, distribution, and reproduction in any medium, provided the original work is properly credited. The Creative Commons Public Domain Dedication waiver (http:// creativecommons.org/publicdomain/zero/1.0/) applies to the data made available in this article, unless otherwise stated. 
The wheat tribe Triticeae (Poaceae) includes many different auto- and allopolyploid taxa, and has received considerable study of its systematics, genetics and speciation [9-11]. One example of a polyploid complex within that tribe Triticeae is the genus Elymus L. sensu lato delimited by Löve [12]; it is an important perennial genus with approximately 150 species worldwide. It includes the traditional species of Elymus L., Roegneria C. Koch, Hystrix Moench, Sitanion Raf., and Kengyilia C. Yen et J. L. Yang.

Since Elymus L. was first described as a genus by Linnaeus [13], its circumscription and taxonomy has changed through times but is still uncertain because of the huge morphological variation within and between species, the polyploid origin of the genus and the frequent spontaneous hybridizations between species [12, 14-16]. Löve [12] suggested that the taxonomic treatment for Triticeae species should be based on genomic constitution, recognizing $\mathrm{StH}$ to be the genomes of Elymus. Dewey [9] accepted Löve's opinion but note the $\mathrm{Y}$ genome was represented in many Asiatic species, recommending that the genomic constitutions of Elymus should be StH, StY or StYH. Roegneria has been recognized a part of Elymus based on morphological characters: tufted plants; similar spikelets, one spikelet per node; lemma lanceolate-oblong, rounded ab-axially, 5-veined and veins connivent at apex; also they have a limited genomic relationship [10, 17, 18]. Although Roegneria shares one or more characteristics with Agropyron, Elymus, and Kengyilia, none have them in the same combination. Therefore, Baum et al. $[19,20]$ concluded that the genus Roegneria should be treated as a strictly separate from Agropyron, Elymus, and Kengyilia. The genus Hystrix was established by Moench with the $H y$. patula as the type based on morphological character of lacking glumes, or possessing subulate or linearsetiform ones [21]. Dewey [9] and Löve [12] proposed to put Hystrix in Elymus based on the fact that Hy. patula contains the StH genome. However, it was suggested that species of Hystrix containing NsXm genomes, such as Hystrix coreana, Hy. duthiei ssp. duthiei and $H y$. duthiei ssp. longearistata should be transferred into Leymus Hochst [22, 23]. The genus Sitanion Rafinesque was erected in 1819, and the type species was Sitanion hystrix. However, Sitanion hystrix and its varieties were treated as Elymus hystrix on the basis of cytogenetic studies [9, 24, 25]. The genus of Kengyilia C. Yen et J. L. Yang was described with Kengyilia gobicola C. Yen et J. L. Yang as the type species, which contains StYP genomes [26]. Based on the principle that taxonomic treatment should reflect phylogenetic history, Yen et al. [27] suggested that the genus Elymus s. l. should be split into Elymus sensu stricto (StH genome), Roegneria C. Koch (StY genome), Australoroegneria C. Yen \& J. L. Yang (later renamed Anthosachne Steudel) (StYW genome),
Campeiostachys Drob. (StYH genome), Douglasdeweya C. Yen, J. L. Yang \& B. R. Baum (StP genome), and Kengyilia C. Yen et J. L. Yang (StYP genome) [28]. This change has been supported by a few taxonomists $[8,18$, 27-32]. Also, some systematists have treated Elymus s. 1. species as different genera, based on differences in morphology and the regional distribution of those polyploid species [27, 30, 32].

All Elymus s. l. species are allopolyploids ranging from tetraploids, hexaploids to octaploids [12]. Cytogenetic analyses suggested that the St-, H-, P-, W-genome originated from Pseudoroegneria (Nevski) Á. Löve, Hordeum L., Agropyron J. Gaertn., and Australopyrum (Tzvelev) Á. Löve, respectively $[9,12,33]$. No putative $Y$ genome diploids have yet been identified [6, 9, 27,33-35]. The St genome is the shared donor genome of the Elymus s. l. species which have StH, StY, StP, StYP, StYH and StYW genomes.

Several dioploid species with St genome in Pseudoroegneria occur from Ciscaucasica to the Middle East and Northern China, and on to western North America [12]. However, the evolutionary pathway of the St genome from dioploid Pseudoroegneria to Elymus s. 1. via hybridization and polyploidization is still unclear.

Gaining a better understanding of the evolutionary history of polyploids is important to the study of plant evolution [1]. Molecular phylogenetic analyses have aided in this process [1, 36, 37]. Nuclear internal transcribed spacer (nrITS) DNA sequences have been used to study phylogenetic and genomic relationships at lower taxonomic levels [38-41]. The chloroplast DNA (cpDNA) sequences, including coding and non-coding regions such as $r b c \mathrm{~L}$ gene, matK gene, the intron of $t r n \mathrm{~L}$ and the intergenic spacer of $\operatorname{trn} \mathrm{L}-\operatorname{trnF}$ and $\operatorname{trn} \mathrm{H}-p s b \mathrm{~A}$ are also valuable source of markers for identifying the maternal donors of polyploids with additional capacity to reveal phylogenetic relationships of related species [38, 42-45]. In Elymus s. 1., both nuclear and chloroplast genes have been used to identify genome donnors, to demonstrate hybridization events or introgression, to examine duplicate gene evolution, and to reveal the evolutionary history and origin of its species [38, 2, 3, 6-49].

In the present study, we analyzed the 6 accessions of 4 Pseudoroegneria species with St genome, 35 accessions of 12 other diploid species with P, W, V, H, I, E, Xp, Ns monogenome, and 28 Elymus s. l. allotetraploids using one internal transcribed spacer region of nuclear gene (nrDNA ITS) and two chloroplast genes (matK and the intergenic region of

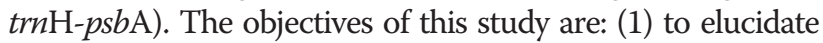
the phylogenetic relationships of some Elymus s. l. polyploid species; (2) to examine the genetic differentiation of St genome in Pseudoroegneria; (3) to investigate the genetic differentiation of St genome in polyploid Elymus s. 1. relative to each other and Pseudoroegneria; (4) to compare the nucleotide diversity of the St-genome sequences of nrITS, matK, 
and $t r n \mathrm{H}-p s b \mathrm{~A}$ between Elymus s. 1. and its putative diploid donors and among Elymus s. 1. species.

\section{Results}

\section{Phylogeny analysis}

nrITS analysis

With the assumed nucleotide frequencies A: 0.21490, C: 0.26170 , G: $0.27980, \mathrm{~T}: 0.24360$, the nrITS data yielded a single phylogenetic tree $(-$ Lnlikelihood $=3004.4870)$, the proportion of invariable sites $=$ none, gamma shape parameter $=0.5849$. Likelihood settings from best-fit model $($ GTR + G) selected by Akaike information criterion (AIC) in Modeltest 3.7. The ML tree with bootstrap support (BS) above branches was illustrated in Fig. 1. We obtained St-, P-, H-type nrITS sequences from our Elymus s. 1. species.

The nrITS sequences from polyploidy were split into five clades (Clade A-E). Clade A included the St-genome sequences of Pseudoroegneria spicata, Pse. stipifolia, and nineteen Elymus s. l. species (Anthosachne australasica, An. scabra except PI533213; Campeiostachys breviaristata ZY0465, C. dahurica var. clyindrica, C. dahurica var. tangutorum Pr88-89 110, C. kamoji, C. nutans; Kengyilia melanthera Y9509; Roegneria anthosachnoides, $R$. grandis, $R$. stricta Y2388; Elymus canadensis PI531567, E. caninus PI531570, E. elymoides, E. hystrix except PI372546, E. mutabilis, E. sibiricus except ZY09243 and ZY09301, E. virginicus except $\operatorname{Pr} 88-89-114, E$. wawawaiensis) and the $E^{\mathrm{e}}$ genome sequence of Lophopyrum elongatum and $\mathrm{E}^{\mathrm{b}}$ genome sequence of $L$. bessarabicum. Clade B consisted of the P-genome sequences of Agropyron cristatum and four Kengyilia species ( $K$. gobicola, K. kokonorica, K. melanthera
Y2078, Y3044 and K. hirsuta Y3068) species (76 \% BS). In the Clade C, Dasypyrum villosum and nine Elymus s. 1. species (Roegneria ciliaris, $R$. ciliaris var. japonensis, $R$. ugamica, R. pendulina, R. stricta Y2137 and Y2157; Campeiostachys dahurica var. tangutorum Y2546; Elymus canadensis POT121, E. caninus PI499413, PI564910 and E. virginicus Pr88-89-114) were gathered together. Two Pseudoroegneria species (Pse. libanotica, Pse. strigosa ssp. aegilopoides) and two Elymus s. 1. species (Campeiostachys breviaristata PI262353; Elymus repens) formed Clade D. Hordeum species (H. bogdanii and $H$. chilense) and the H-genome sequences of six Elymus s. 1. species (Campeiostachys breviaristata ZY3036, C. dahurica var. tangutorum ZY09246; Elymus caninus PI314621 and PI499412, E. canadensis PI236805, E. hystrix PI327546, E. sibiricus ZY09243 and ZY09301) comprised Clade E.

\section{matK analysis}

The ML analysis of the mat $\mathrm{K}$ sequence data yielded a single phylogenetic tree $(-$ Lnlikelihood $=1787.3855)$, with the assumed nucleotide frequencies A: 0.36600; C: 0.15890; G: 0.17570 ; $\mathrm{T}: 0.29940$, the proportion of invariable sites $=$ none, gamma shape parameter $=0.8381$. Likelihood settings from best-fit model $(\mathrm{TVM}+\mathrm{G})$ were selected by AIC in Modeltest 3.7. We found all matk sequences from Elymus s. l. species corresponded to the St-type.

The tree illustrated in Fig. 2 was ML tree for the matK data with BS above branches. All the Elymus s. l. species and some diploid species of the Triticeae formed Clade I. The other diploid species were put outside Clade I. Within Clade I, the St-genome sequences of the following formed one subclade: all Pseudoroegneria species, the $\mathrm{E}^{\mathrm{e}}$ genome
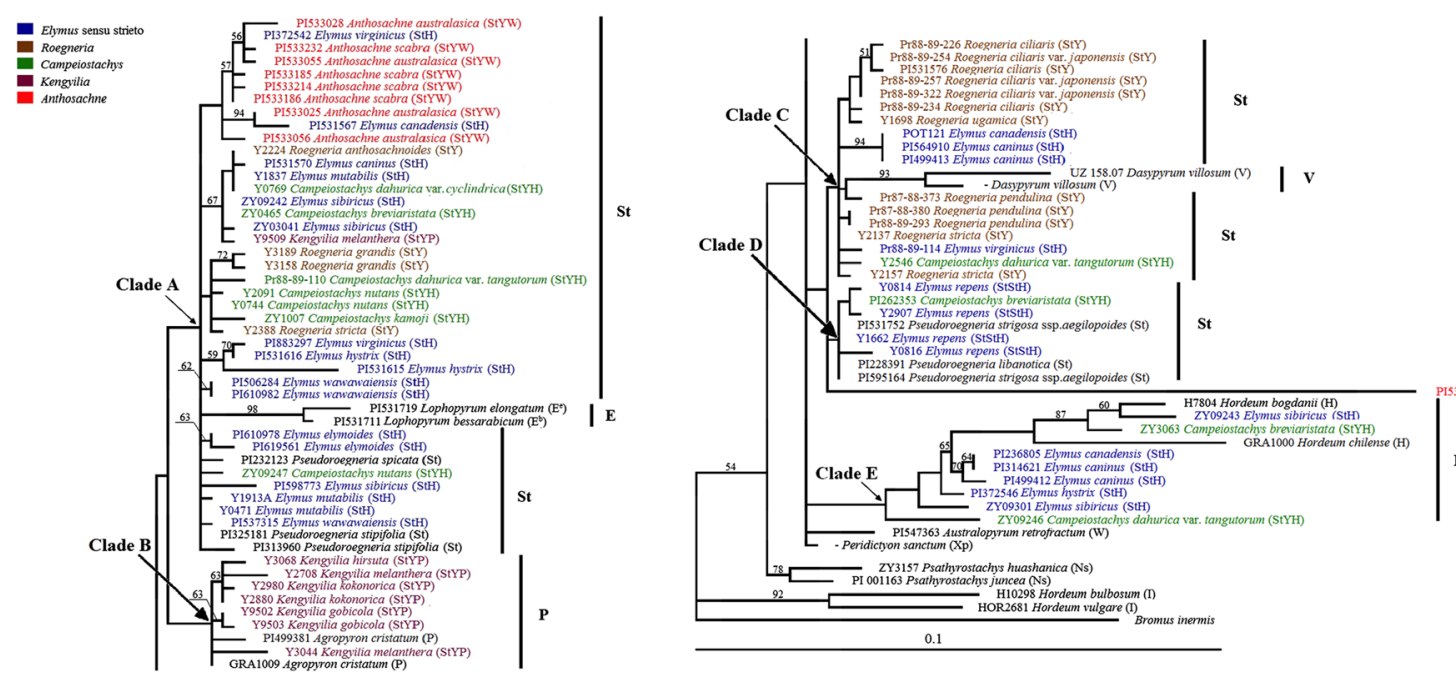

Fig. 1 Maximum-likelihood tree (-Lnlikelihood = 3004.4870, base frequencies A: 0.21490, C: 0.26170, G: 0.27980, T: 0.24360, pinvar = none, shape =0.5849) inferred from the nrlTS sequences of Elymus $L$. sensu lato and its affinitive species, under GTR $+G$ model. Numbers with bold above nodes are bootstrap values $\geq 50 \%$. The capital letters in bracket indicate the genome type of the species. Different color labeled the genera of Elymus L. sensu lato species 


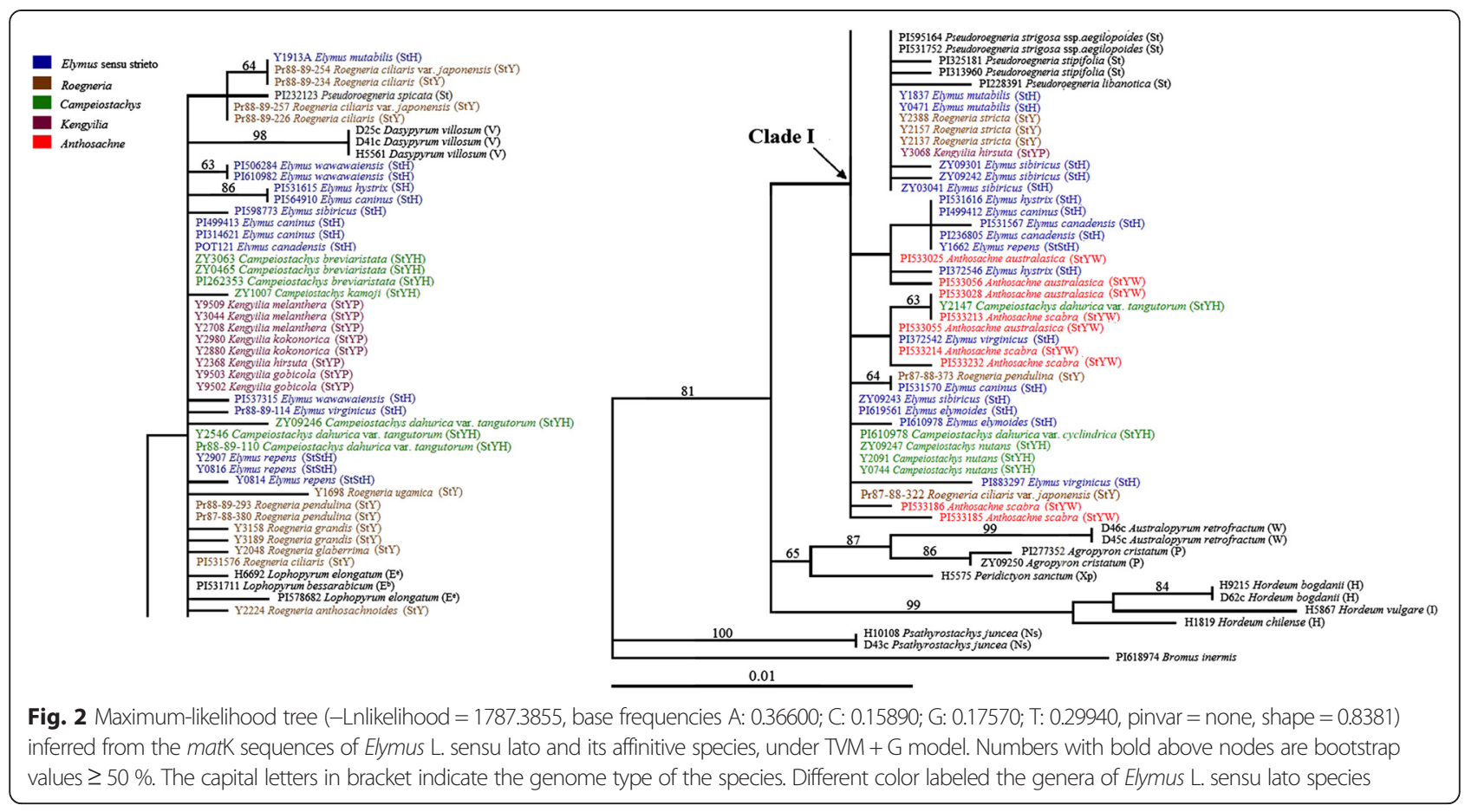

sequence of Lophopyrum elongatum, the $\mathrm{E}^{\mathrm{b}}$ genome sequence of $L$. bessarabicum, the $\mathrm{V}$ genome sequence of Dasypyrum villosum and twenty-three Elymus s. l. species (Campeiostachys breviaristata, C. dahurica var. tangutorum except Y2147, C. kamoji; Kengyilia gobicola, K. kokonorica, K. melanthera except Y9059, K. hirsuta; Roegneria anthosachnoides, $R$. ciliaris, $R$. ciliaris var. japonensis except Pr87-88-322, $R$. glaberrima, $R$. grandis, $R$. pendulina except Pr87-88-373, R. ugamica, R. stricta; Elymus repens except Y1662, E. canadensis POT121, E. caninus except PI499412 and PI531570, E. hystrix PI531615, E. mutabilis, E. sibiricus except ZY09243, E. virginicus Pr88-89-114, E. wawawaiensis). The other fourteen Elymus s. 1. species (Anthosachne australasica, An. scabra; Campeiostachys dahurica var. clyindrica, $C$. dahurica var. tangutorum Y2147, C. nutans; Roegneria pendulina, R. ciliaris var. japonensis Pr87-88-322; Elymus canadensis except POT121, E. caninus PI499412 and PI531570, E. elymoides, E. hystrix except PI531615, E. repens Y1662, E. sibiricus ZY09243, E. virginicus except Pr88-89-114) were placed outside the subclade and formed a paraphyletic grade with a number of zerolength branches in the Clade I.

\section{trnH-psbA analysis}

Likelihood settings from best-fit model $(\mathrm{K} 81 \mathrm{uf}+\mathrm{G})$ were selected by AIC in Modeltest 3.7 (-Ln likelihood = 1174.7281). The assumed nucleotide frequencies $A$ : 0.35970; C: 0.17790; G: 0.18010; T: 0.28230, the proportion of invariable sites $=$ none, gamma shape parameter $=$
0.1481. The ML tree with BS above branches was illustrated in Fig. 3. We obtained two different St-type trnHpsbA sequences from Elymus s. l. species.

Pseudoroegneria stipifolia, Pse. strigosa ssp. aegilopoides PI531752 and twelve Elymus s. 1. species (Anthosachne: An. australasica PI533055, An. scabra except PI533186 and PI533213; Campeiostachys: C. breviaristata except ZY3036, C. kamoji and C. nutans Y0744; Kengyilia: K. gobicola, K. hirsuta, K. kokonorica, K. melanthera except Y2708; Elymus: E. wawawaensis PI610982, E. virginicus PI372542 and E. sibiricus except ZY09243) were placed outside the Clade One, forming a paraphyletic grade with a number of zerolength branches in the ML tree inferred from the trnHpsbA data. Within Clade One, Pse. libanotica, Pse. strigosa ssp. aegilopoides PI595164, Pse. spicata, $\mathrm{E}^{\mathrm{e}}$ genome sequence of Lophopyrum elongatum and the $\mathrm{E}^{\mathrm{b}}$ genome sequence of Lo. bessarabicum were grouped with the other Elymus s. 1. species. The $\mathrm{H}$ and I genome sequence of Hordeum species (H. bogdanii, H. chilense, H. vulgare) and the $\mathrm{V}$ genome sequence of Dasypyrum villosum were placed at the bottom of the Clade One.

\section{MJ-network analysis}

As no recombination was detected using the GARD recombination-detection method within the HyPhy package, nrITS, matK, and trnH-psbA sequences obtaitned in this study were used to generate MJ network. Each circular network node represents a single sequence haplotype, with node size being proportional to number of isolates with that haplotype. Median vectors (mv representing 


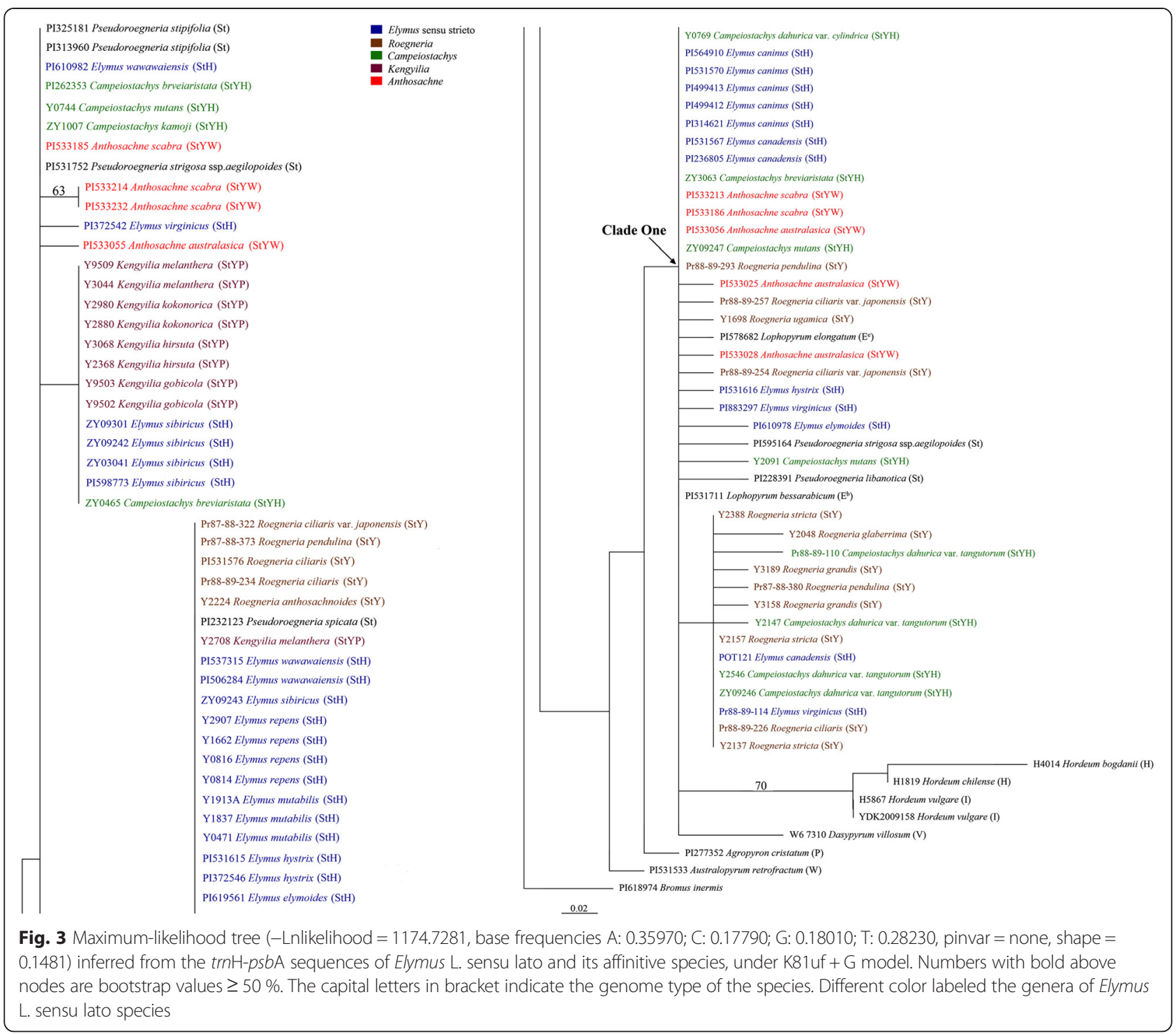

missing intermediates) show unsampled nodes inferred by $\mathrm{MJ}$ network analysis, and the number along the branches shows the position of mutations. Different species sharing a same haplotype circular network node were represented by distinct colors. Network loops represent either true reticulation events or alternative genealogies in closely related lineages.

Seventy-six, forty-eight, and thirty-three haplotypes were derived from 98 nrITS sequences (Fig. 4), 102 mat $\mathrm{K}$ sequences (Fig. 5), and 95 trn $\mathrm{H}-p s b \mathrm{~A}$ sequences (Fig. 6), separately. We found median-joining (MJ) network showed a consistent phylogenetic reconstruction with ML tree. We identified those clusters' name following the group name showed in the ML tree to make it clearly concerted. In the nrITS MJ network analysis, five clusters (Cluster N-A to Cluster N-E) representing three distinct types of haplotypes (St-, P-, and H-type) of Elymus s. 1. In the matK MJ-network analysis, all the species with St genome clustered together with St diploid species in Cluster N-I. The trnH-psbA MJ network analysis recognized two different St-types of haplotypes of Elymus s. l. species, grouped in Cluster $\mathrm{N}-$ One and N-Two.

\section{Nucleotide diversity analysis in St genome}

Two measures of nucleotide diversity $\pi$ and $\theta w$, were separately calculated for each set of sequence data for the St genome of the diploid species (Pseudoroegneria), tetraploid StH and StY species and hexaploid StYW, $\mathrm{StYH}, \mathrm{StYP}$ and StStH species. The Tajima's test and Fu and Li's test were conducted on each of different genome composing data sets (Table 1). 


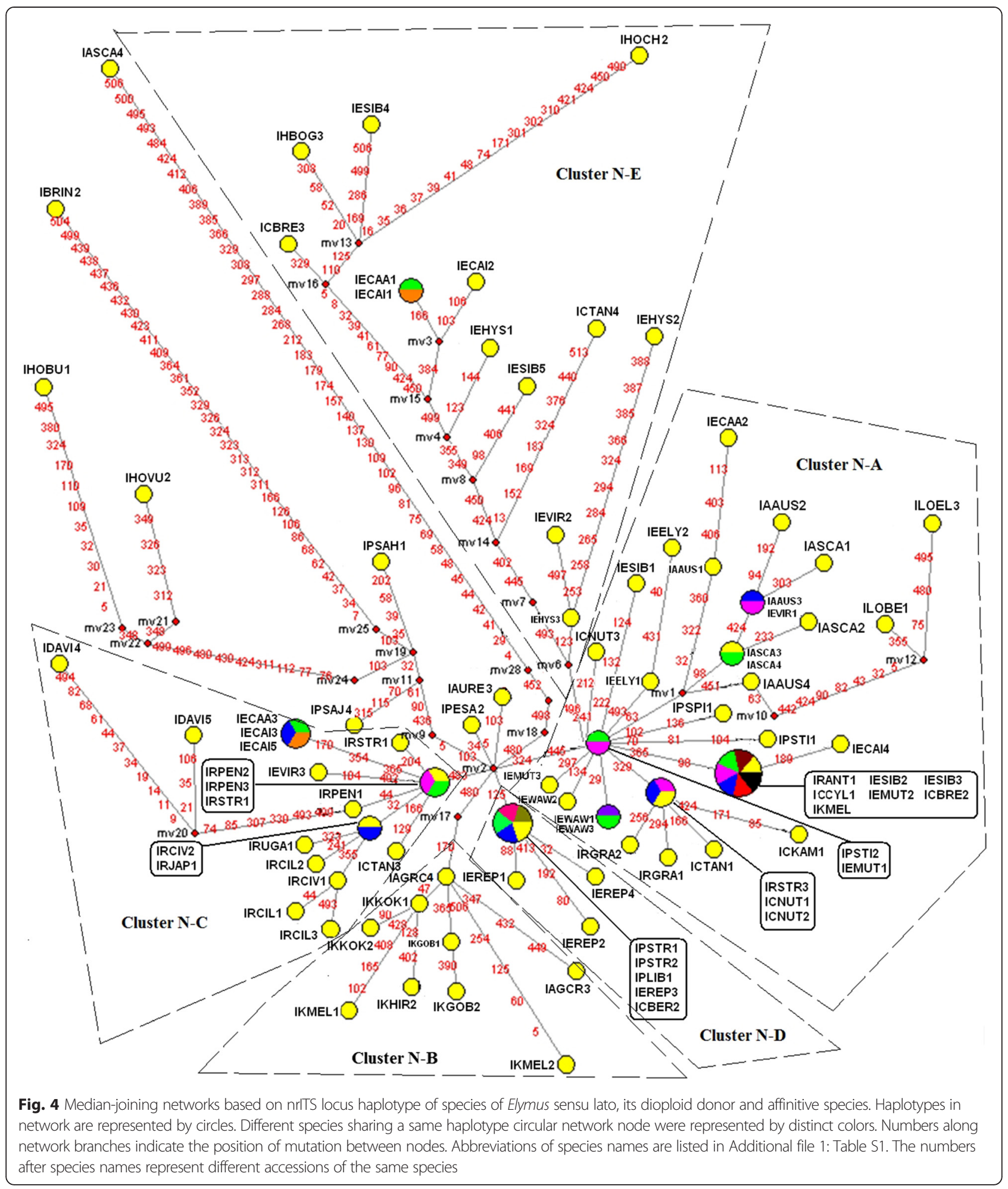

The St-type nrITS sequence of StYP species is missing from our data, thus we cannot report nucleotide diversity for that category. trn $\mathrm{H}-p s b \mathrm{~A}$ sequences obtained from the StStH species (Elymus repens) were identical, in that case nucleotide diversity was zero. Tajima's and $\mathrm{Fu}$ and Li's D estimate for the trn $\mathrm{H}-p s b \mathrm{~A}$ sequences from St genome species and Tajima's D estimate for the trn $\mathrm{H}-p s b \mathrm{~A}$ sequences from StYW genome species were 


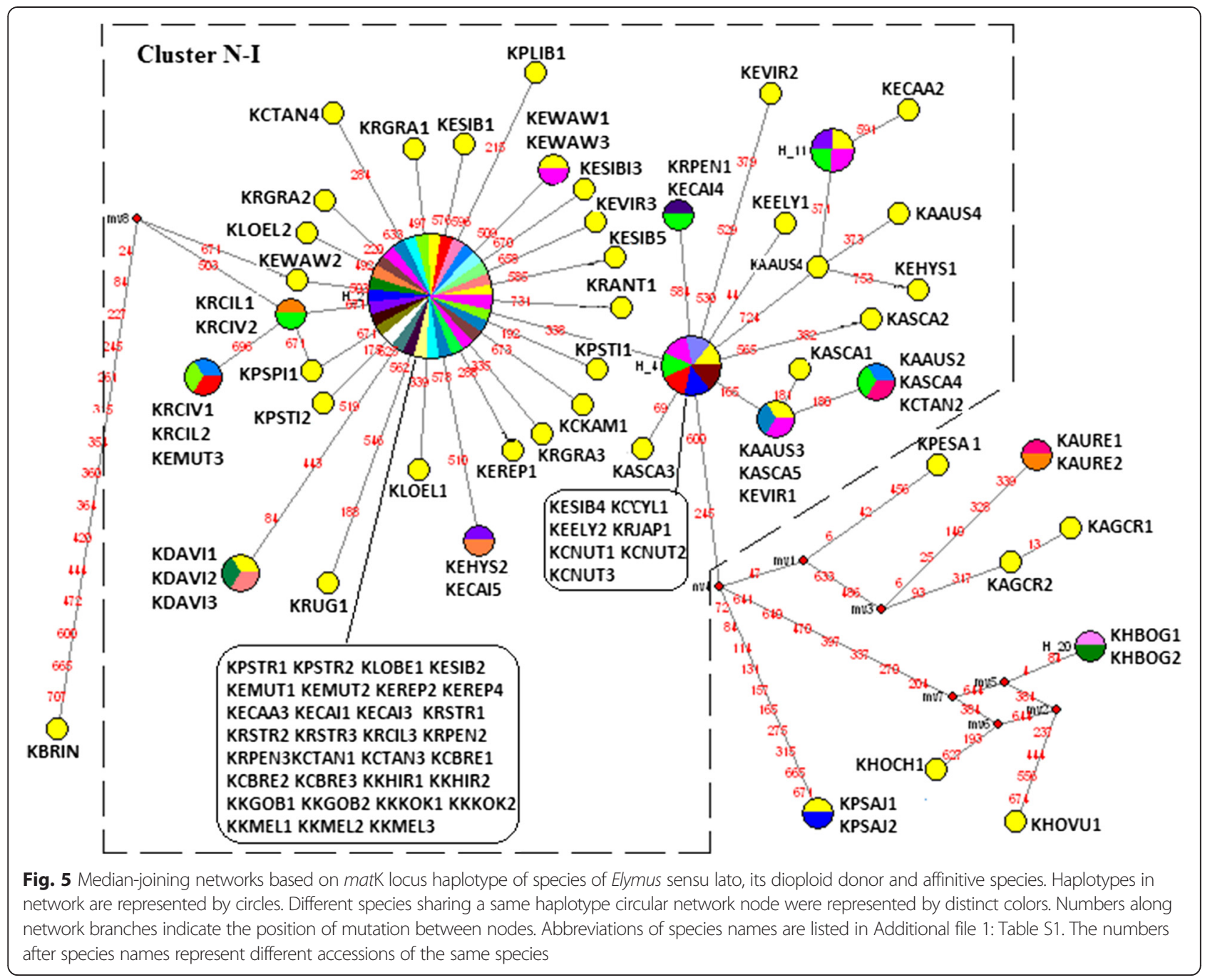

positive, indicating a departure from the equilibrium neutral model at this locus, with an excess of rare sequence variants in the St genome diploid species and StYW genome hexaploid species based on trnH-psbA sequences.

\section{Discussion}

Phylogenetic relationships among the polyploids in Elymus s. I.

Elymus s. 1. consists of allopolyploids that are widely distributed and includes a number of endemic species. Analyses of nrITS, matK and trn $\mathrm{H}-p s b \mathrm{~A}$ sequences collected from a wide range of Elymus s. 1. species and related genera can shed light on their phylogenetic relationships, ancestral donors and the polyploidization events in the speciation processes on the basis of orthologous comparison.

The genus Campeiostachys was established using morphology based on a single species Campeiostachys schrenkiana (Fisch. \& Mey. ex Schrenk) Drobov [50]. Baum et al. [32] suggested keeping the genus name Campeiostachys Drobov for the allohexaploid species with the genomic constitution StStHHYY which admittedly cannot be separated morphologically from the traditional genus Elymus. For example, based on the genome constitution, Elymus breviaristatus Keng was treated as Campeiostachys breviaristata (Keng) Y. H. Zhou, H. Q. Zhang et C. R. Yang. According to Yen et al. [51], Elymus tangutorum (Nevski) Hand. -Mazz was treated as Campeiostachys dahurica var. tangutorum in the $C$. dahurica complex [52]. Subtle morphological differences have often formed the basis for taxon recognition within the complex, resulting in different taxonomic treatments of the Elymus dahurica complex. The species complex possesses three haplomes St, $\mathrm{Y}$, and $\mathrm{H}$ with $2 \mathrm{n}=6 \mathrm{x}=42$ chromosomes and has an Asiatic distribution, ranging from Iran to Japan and from southern Siberia to central China [12]. Molecular diversity of the 5S rDNA units [53], storage proteins 


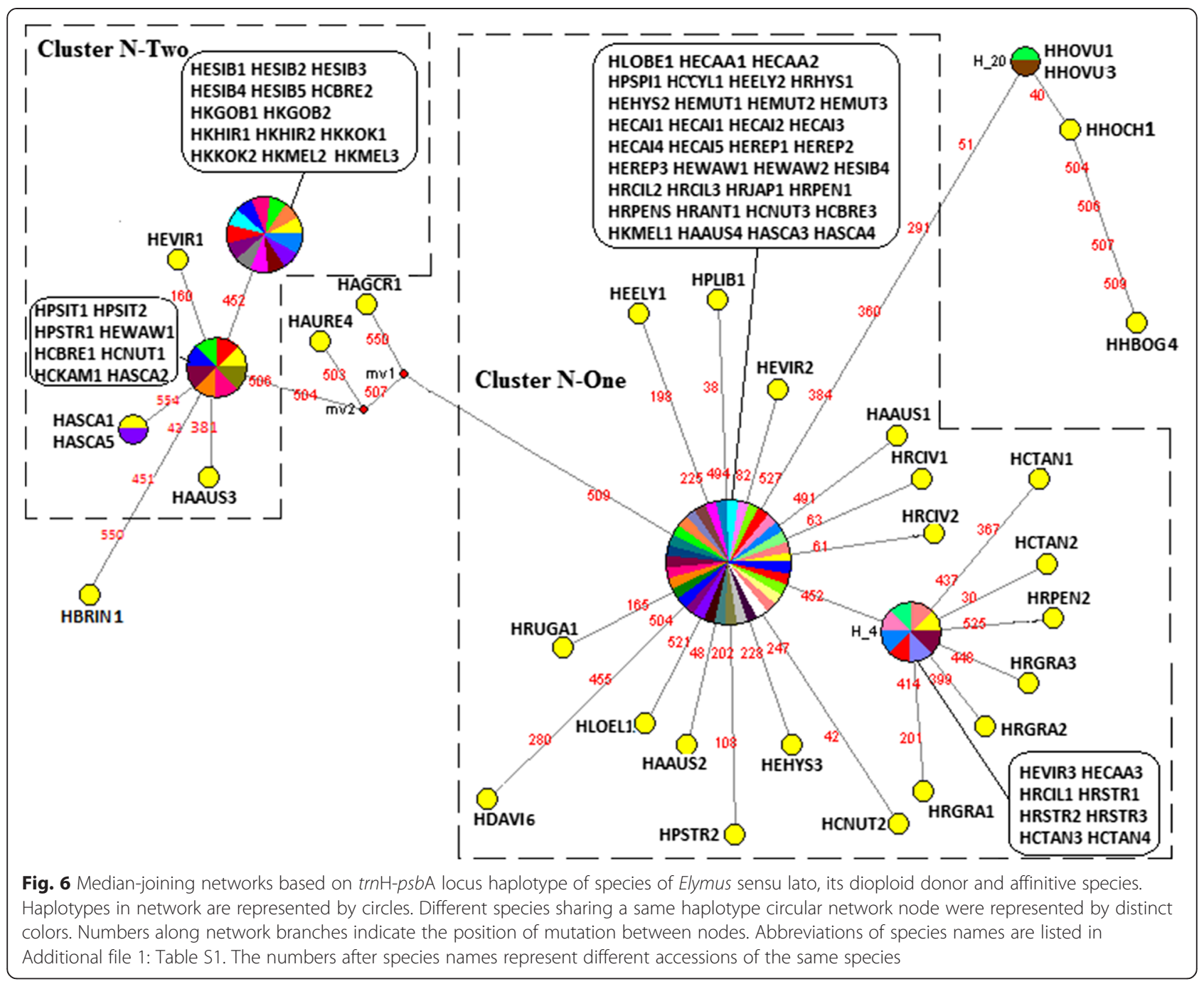

[54], and other considerations [55] in the Elymus dahurica complex supported the genomic constitution of St, Y, and $\mathrm{H}$ haplomes. The ML tree and MJ network based on nrITS data from this study, combined with unpublished GISH (Genomic in situ hybridization) results, confirms the genomic constitution of St, $\mathrm{Y}$, and $\mathrm{H}$ haplomes in $E$. tangutorum and E. breviaristatus. Morphologically, E. tangutorum and E. breviaristatus are similar to the species in Campeiostachys in that they share the chatacteristic of palea and lemma having equal length [51]. Despite subtle morphological differences in these species, we strongly support the taxon treatment based on both genomic constitution and morphology. Thus, E. tangutorum should be treated as $C$. dahurica var. tangutorum and $E$. breviaristatus should be transferred into Campeiostachys.

It has been found recently that incomplete concerted evolution of nrDNA is widespread among angiosperms [56]. The frequency of heterogeneity among rDNA sequences is higher in alloployploids than that in diploid and autopolyploid species [57]. The main cause of heterogeneity is slowed concerted evolution due to hybridization and polyploidy. Concerted evolution in an allopolyploid may lead to a novel combination of nrITS sequences representing a mixture of the two original parental nrITS sequences that occur within a single individual. It is also possible that unidirectional concerted evolution could subsequently occur, leading to the loss of one copy and fixation of the new nrITS type. Furthermore, both types of parental sequences of the nrITS region could be maintained, especially in the case in young hybridderived taxa that have had little opportunity for concerted evolution [57-59]. In the present ML analysis, Anthosachne scabra (StYW, PI533213, Australia) was placed at abnormal branches site with St-type nrITS sequences obtained from Pse. libanotica (St, Middle East), Pse. strigosa ssp. aegilopoides (St, PI595164, Central Asia; PI531752, Middle East), Roegneria (StY, Central Asia), Campeiostachys (StYH, Central Asia) and Elymus (StH, Central Asia and StStH, Central Asia). Additionally, a GA/GT insert at position 119-122 in the ITS sequence was detected for 
Table 1 Estimates of nucleotide diversity and test statistics at nrlTS, matK and trnH-psbA locus on St-genome in species of Elymus sensu lato

\begin{tabular}{|c|c|c|c|c|c|c|c|}
\hline & Gene & $n$ & s & $\pi$ & $\theta w$ & Fu \& Li's D & Tajima's D \\
\hline \multirow[t]{3}{*}{ StH species } & nrlTS & 512 & 46 & 0.0142 & 0.0250 & $-2.2572(0.10>P>0.05)$ & $-1.7192(0.10>P>0.05)$ \\
\hline & matk & 750 & 20 & 0.0035 & 0.0069 & $-2.5829(P<0.05)$ & $-1.7801(0.10>P>0.05)$ \\
\hline & $\operatorname{trnH}-p s b \mathrm{~A}$ & 559 & 10 & 0.0039 & 0.0046 & $-1.2038(P>0.10)$ & $-0.5366(P>0.10)$ \\
\hline \multirow[t]{3}{*}{ StY species } & nrlTS & 499 & 22 & 0.0108 & 0.0133 & $-0.8768(P>0.10)$ & $-0.7672(P>0.10)$ \\
\hline & matk & 751 & 11 & 0.0024 & 0.0043 & $-1.8900(P>0.10)$ & $-1.6981(0.10>P>0.05)$ \\
\hline & $\operatorname{trnH} \mathrm{H}-p s b \mathrm{~A}$ & 559 & 9 & 0.0026 & 0.0048 & $-2.5326(P<0.05)$ & $-1.6134(0.10>P>0.05)$ \\
\hline \multirow[t]{3}{*}{ StYW species } & nrlTS & 516 & 14 & 0.0077 & 0.0105 & $-1.4635(P>0.10)$ & $-1.3534(P>0.10)$ \\
\hline & matk & 751 & 8 & 0.0032 & 0.0039 & $-0.7308(P>0.10)$ & $-0.7695(P>0.10)$ \\
\hline & $\operatorname{trnH}-p s b \mathrm{~A}$ & 565 & 9 & 0.0062 & 0.0059 & $-0.1073(P>0.10)$ & $0.2621(P>0.10)$ \\
\hline \multirow[t]{3}{*}{ StYP species } & nrlTS & - & - & - & - & - & - \\
\hline & matk & 754 & 4 & 0.0019 & 0.0020 & $-0.2642(P>0.10)$ & $-0.0754(P>0.10)$ \\
\hline & $\operatorname{trnH}-p s b \mathrm{~A}$ & 564 & 5 & 0.0020 & 0.0033 & $-1.8812(0.10>P>0.05)$ & $-1.6775(0.10>P>0.05)$ \\
\hline \multirow[t]{3}{*}{ StYH species } & nrlTS & 513 & 18 & 0.0104 & 0.0129 & $-0.7412(P>0.10)$ & $-0.9514(P>0.10)$ \\
\hline & matk & 750 & 6 & 0.0018 & 0.0027 & $-1.7133(P>0.10)$ & $-1.1962(P>0.10)$ \\
\hline & $\operatorname{trnH}-p s b \mathrm{~A}$ & 560 & 10 & 0.0059 & 0.0060 & $-0.5505(P>0.10)$ & $-0.0104(P>0.10)$ \\
\hline \multirow[t]{3}{*}{ StStH species } & nrlTS & 515 & 6 & 0.0062 & 0.0064 & $-0.3145(P>0.10)$ & $-0.3145(P>0.10)$ \\
\hline & matk & 754 & 4 & 0.0027 & 0.0029 & $-0.7801(P>0.10)$ & $-0.7801(P>0.10)$ \\
\hline & $\operatorname{trnH}-p s b \mathrm{~A}$ & - & - & - & - & - & - \\
\hline \multirow[t]{3}{*}{ Pseudoroegneria } & nrlTS & 514 & 9 & 0.0079 & 0.0077 & $-0.0922(P>0.10)$ & $-0.1890(P>0.10)$ \\
\hline & matk & 753 & 5 & 0.0022 & 0.0029 & $-1.3683(P>0.10)$ & $-1.3370(P>0.10)$ \\
\hline & $\operatorname{trn} \mathrm{H}-p s b \mathrm{~A}$ & 564 & 8 & 0.0066 & 0.0062 & $0.0777(P>0.10)$ & $0.3865(P>0.10)$ \\
\hline
\end{tabular}

The $n$ is the number of the sites (excluding sites with gaps/missing data), $s$ is the number of segregating sites, $\pi$ is the average pairwise diversity, and $\theta_{w}$ is the diversity based on the number of segregating sites.

the Roegneria species in Clade C. At the same position, a GGT/AT insert in the nrITS sequence was detected for the Elymus, Pseudoroegneria and Anthosachne scabra (StYW, PI533213, Australia) species in Clade D. A CCAC insert at position 417-420 was detected for all species mentioned. And, these two clades were very close to each other. Thus, we hypothesized that the nrITS type obtained from this group might be a mid-type, representing a mixture of the two ancestral nrITS sequences (St-and St-Ytype). This situation may be due to inter-genome recombination, following hybridization either before or after the chromosome doubling event. Furthermore, Pseudoroegneria from Central Asia might have acted as an ancestor in the hybrid history of Roegneria (StY, Central Asia), resulting recombination sequences. Previous findings on the evolution of nrITS sequences in allopolyploids are typically similar to our findings; sequences that represent some combination of ancestral input $[60,61]$.

\section{The differentiation of St genome in Elymus s. I.}

Prior research has demonstrated the evolutionary differentiation of the St genome in different diploid species. Considering the morphological differentiation of Pseudoroegneria,
Pse. stipifolia has rough rachis densely covered by prickles; P. spicata has slender awns and unequal glumes; Pse. strigosa has long awns with equal glumes; but Pse. tauri and Pse. libanotica have no awns with unequal glumes [62]. The molecular data also shows differentiation in Pseudoroegneria. Sun et al. [63] reported a 39 bp MITE stowaway element insertion in the region of nuclear RNA polymerase II (RPB2) gene for Pse. spicata and Pse. stipifolia; Pse. tauri and Pse. libanotica lack this insertion. The Pseudoroegneria diploid species are widely distributed extending from Ciscaucasica to Middle East and Central Asia, and on to western of North America [12]. In our study, Pse. libanotica (Middle East), Pse. strigosa ssp. aegilopoides (PI595164, Central Asia; PI531752, Middle East), Pse. stipifolia (Central Asia), and Pse. spicata (North America) were used in the phylogenetic analysis based on the nrITS, matK and $t r n \mathrm{H}-$ psbA data. All Elymus s. l. species grouped with the Pseudoroegneria species in the ML tree and MJ network using the matK data. Although in the ML tree and MJ network based on the trnH-psbA data, Pse. stipifolia from Central Asia and Pse. strigosa ssp. aegilopoides (PI531752) from Middle East were closely placed with six Elymus s. l. tetraploids and sixteen Elymus s. 1. hexaploids, Pseudoroegneria 
libanotica and Pse. strigosa ssp. aegilopoides (PI595164) from Middle East and Central Asia, Pse. spicata from North America were grouped with the rest Elymus s. 1 . species. Similar results were obtained in the ML tree and MJ network based on the nrITS sequence data. Collectively, the results implied that the Pseudoroegneria species from Central Asia and Middle East are more ancient than those from North America. Obviously, the differentiation exists in the diploid Pseudoroegneria species from Middle East, Central Asia and North America. The formation of Pseudoroegneria species appear to have originated in the Central Asia and Europe, later spreading to North America.

In this study, based on the matK data, all the Elymus s. 1 . species were grouped with the Pseudoroegneria species (with sub-clades) in the ML tree and MJ network. In contrast, the ML tree and MJ network based on the $\operatorname{trn} \mathrm{H}$ psbA data closely placed Pse. stipifolia from Central Asia and Pse. strigosa ssp. aegilopoides (PI531752) from Middle East with three tetraploids (E. wawawaensis, E. virginicus and $E$. sibiricus) and nine hexaploids (C. breviaristata, $C$. kamoji, C. nutans, An. australasica, An. scabra, K. gobicola, K. hirsuta, K. kokonorica and K. melanthera). Pseudoroegneria libanotica and Pse. strigosa ssp. aegilopoides (PI595164) from Middle East and Central Asia, Pse. spicata from North America were grouped with the rest Elymus s. 1. species. Similar results were obtained from the ML tree based on the nrITS sequence data. The evolution of Elymus s. l. species might appears to parallel that of the Pseudoroegneria species, originating in Central Asia and Europe, then spreading to the North America via recurrent hybridization and polyploidization events. In addition, Elymus s. l. species were split into different St-groups. For instance, two accessions of hexaploid C. breviaristata were placed in separate St-genome clade in the ML tree based on the nrITS and trnH-psbA sequence data. The same situation was also detected in the tetraploid $E$. canadensis in the ML tree based on the matK and trn H-psbA sequence data. Such patterns indicate that differentiation of St genome existed in the species of Elymus s. l. at both the genus and species after polyploidization event based on the nrDNA ITS and the chloroplast matK and trn $\mathrm{H}-p s b \mathrm{~A}$ molecular data. We also found non-coding cpDNA sequences $(\operatorname{trn} \mathrm{H}-p s b \mathrm{~A})$ provided more phylogenetic information than coding cpDNA sequences (mat $\mathrm{K})$, revealing the differentiation of St genome in Elymus s. 1. species more clearly.

Evolutionary dynamics of duplicate genes can provide a better understanding of the processes of polyploidization and subsequent rapid diversification [1, 4]. In this study, nrITS and matK nucleotide sequence diversity of the St genome of tetraploid $\mathrm{StH}$ and $\mathrm{StY}$ tetraploid species was higher than in the St genome of diploid Pseudoroegneria. Tajima's and Fu and Li's D estimate for the trnH-psbA in the St genome of diploid Pseudoroegneria was positive. This result indicated a departure from the equilibrium neutral model at this locus, with an excess of rare sequence variants in the diploid Pseudoroegneria species. This finding is compatible with a genetic bottleneck created by recent polyploidization during radiation of Pseudoroegneria species. The values of Tajima's and Fu and Li's $D$ statistic for nrITS, matK and $t r n \mathrm{H}-p s b \mathrm{~A}$ sequence on $\mathrm{StH}$ and StY genome were all negative, indicating that the observed number of rare variations exceeds the expected number in an equilibrium neutral model. These estimates indicated that the excess of rare variants in tetraploid $\mathrm{StH}$ and StY species might be created by different independent hybridization event or introgression of St genome during polyploidization.

Our phylogenetic results support the possibility that StY tetraploid species was the direct ancestor of the StYW, StYP and StYH hexaploid species during the allohexaploid speciation process (see next discussion section). We compared the nucleotide sequence diversity of the nrITS, matK and $t r n \mathrm{H}-p s b \mathrm{~A}$ between the St genome of StY tetraploid spices and the StYW, StYP and StYH hexaploid spices, respectively. As the narrow distribution of StYW and StYP species and rare species of StYH species compared with $\mathrm{StY}$ species, the nucleotide sequence diversity in the St genome of tetraploid StY species were higher than in the St genome of hexaploid species (StYH and StYW for nrITS, matK sequence, and StYP for matK and trn $\mathrm{H}-p s b \mathrm{~A}$ sequence). In addition, the values of Tajima's and Fu and Li's $D$ statistic for nrITS, matK and trnH$p s b \mathrm{~A}$ gene loci of the St genome of hexaploid StYW, StYP and StYH species (except the Tajima's $D$ for trnH$p s b \mathrm{~A}$ gene on the St genome of hexaploid StYW species) were negative, indicating that the observed number of rare variations exceeds the expected number in an equilibrium neutral model. These estimates indicated that the excess of rare variants in hexaploid StYH, StYW and StYP species also have been created by different independent hybridization or introgression events of St genome during polyploidization.

\section{Putative origins of the polyploids in Elymus s. I.}

Cytogenetical studies have concluded that Pseudoroegneria, Hordeum, Australopyrum, and Agropyron species have served as the St, H, W, and P genome diploid donors, respectively, during the polyploid speciation of Elymus s. 1 . species $[9,17,35]$. In the ML tree based on the nrITS data, three types of nrITS sequences (St-, H- and P-type) were obtained from all the polyploidy Elymus s. 1. species (except the An. scabra PI533213) in the present study. This result indicated that nrITS sequences in different Elymus s. l. species were very similar to their diploid ancestors, confirming that Elymus s. l. is closely 
related to Pseudoroegneria, Hordeum and Agropyron. Combined with the prior cytogenetic results, we can conclude that the Pseudoroegneria, Hordeum and Agropyron species served as the St, $\mathrm{H}$ and $\mathrm{P}$ genome diploid donors during the allopolyploid speciation of Elymus s. $\mathrm{l}$. species. Our conclusion is partly consistent with prior the single-copy nuclear gene data (Acc1 and $P g k 1)$ studies [8]. Those studies also proposed that Australopyrum species served as the $\mathrm{W}$ genome diploid donors during the polyploid speciation of Anthosachne species. We did not obtain W-type nrITS sequences in this study. In a future study the W-type nrITS sequences from Anthosachne might be obtained by screening a larger number positive clones with the nrITS sequence insert to test whether Australopyrum contributed to the evolution of Elymus s. l. species.

Phylogenetic analysis of our nrITS data revealed each homoeologous sequence grouped with those from the corresponding diploid progenitors. Similarly, the homoeologous loci of nrITS from sampled StYH genome Campeistachys species (C. komoji and C. nutans), StYP genome Kengyilia species (K. melanthera) and StYW genome Anthosachne species (An. scabra and An. australasica) were recovered, with each homoeologous locus also grouping with the StY genome Roegneria species ( $R$. anthosachnoid, $R$. grandis and $R$. stricta) and $\mathrm{StH}$ genome Elymus sensu stricto species (E. canadensis, E. caninus, E. elymoides, E. hystrix, E. mutabilis, E. sibiricus, E. virginicus and E. wawawaiensis). These results strongly support the suggestion that the StYH, StYP and StYW genome species had their allohexaploid origin via $\mathrm{StY}$ as one of the hybridizing ancestors. Combined with the previous cytogenetic evidence, relatively large population size of the StY genome Roegneria species and the failure to discover the diploid Y-genome donor, it can be concluded that the StY genome species might serve as a direct donor of the StYH, StYP and StYW genome species during the allohexaploid speciation. These results also suggested a multiple origin of some polyploid species resulting from independent origin. This conclusion is compatible with the hypothesis of Yen et al. [27] and the results of Fan et al. [8]

\section{Conclusion}

In this study, the nrITS sequence analysis in different Elymus s. 1. species showed a clear linkage between nrITS sequences of polyploid Elymus s. 1. species and those of their diploid ancestors. Combined with the previous cytogenetic results, our data supported the premise that Pseudoroegneria, Hordeum and Agropyron species served as the $\mathrm{St}, \mathrm{H}$ and $\mathrm{P}$ genome diploid donors during the polyploid speciation of Elymus s. 1. species. Analyses of phylogenetic relationships based on nrITS data also showed that it is reasonable to treat the E. tangutorum as $C$. dahurica var. tangutorum and transfer the E. breviaristatus into Campeiostachys in spite of subtle morphological differences in these species. We strongly support the taxonomy according to both genomic constitution and morphology. Sequence diversity patterns analyses of the two chloroplast genes suggested that the Pseudoroegneria (St genome donor) served as the maternal donor during the polyploidization events that gave rise to Elymus s. l. Those patterns also suggested that Pseudoroegneria species from Central Asia and Europe were more ancient than those from North America. Elymus s. 1. species appear to have originated in Central Asia and Europe, then spread to the America after the recurrent hybridization and polyploidization events. Furthermore, differentiation of St genome existed at both genus and species level based on the nrDNA ITS and the chloroplast $m a t \mathrm{~K}$ and $t r n \mathrm{H}-p s b \mathrm{~A}$ sequences. The molecular diversity of the two chloroplastid genes and one nuclear DNA sequence in the St genome reflect the evolution of the St genome in the Elymus s. l. The molecular evolution in the St genome may go into a period of nonrandom evolution following the polyploidization event and introgression of St genome departing from the equilibrium neutral model due to a genetic bottleneck caused by recent polyploidization.

\section{Methods}

\section{Taxon sampling}

Twenty-eight Elymus s. 1. species were included in this study and were analyzed together with sixteen diploid taxa representing nine basic genomes in the tribe Triticeae (See Additional file 1: Table S1). Bromus inermis Leyss was used as outgroup. The seed materials with PI numbers were kindly provided by American National Plant Germplasm System (Pullman, Washington, USA). We collected the seed materials with Pr, ZY, and Y numbers. The plants and voucher specimens were deposited at Herbarium of Triticeae Research Institute, Sichuan Agricultural University, China (SAUTI).

\section{DNA extraction, amplification and sequencing}

The CTAB (Cetyltrimethyl Ammonium Bromide) procedure [64] was used to isolate total DNA. The nuclear nrITS sequence, chloroplast mat $\mathrm{K}$ and $\operatorname{trn} \mathrm{H}-p s b \mathrm{~A}$ spacer sequence were amplified with primers listed in Table 2. PCR amplification of the cpDNA was carried out in a $50 \mu \mathrm{L}$ reaction mixture, containing $10 \times$ ExTaq polymerase buffer, $2 \mathrm{mM} \mathrm{MgCl} 2,200 \mu \mathrm{M}$ of dNTP, $1 \mu \mathrm{M}$ of each primer, $1.5 \mathrm{U}$ ExTaq and about $30 \mathrm{ng}$ of template DNA. Amplifications were performed on Mastercycler (Pro S, Eppendorf, Germany) using protocols described in Table 3. The PCR products were visualized on $1.0 \%$ agarose gels, purified by an ENZA $^{\text {tox }}$ gel extraction kit (Omega Bio-Tech, Georgia, USA) and then cloned into pMD19$\mathrm{T}$ vector (TaKaRa, Dalian, China) according to the 
Table 2 Names, sequences, and references of primers used in this study

\begin{tabular}{|c|c|c|c|}
\hline Gene & Name of primers & Sequence of primer $\left(5^{\prime}-3^{\prime}\right)$ & Reference \\
\hline \multirow[t]{2}{*}{ nrlTs } & ITS4 & TCCTCCGCTTATTGATAGC & White et al. [71] \\
\hline & ITS5 & GGAAGTAAAAGTCGTAACAAGG & \\
\hline \multirow[t]{2}{*}{ matK } & W & TACCCTATCCTATCCAT & Hilu et al. [72] \\
\hline & $9 R$ & GCTAGAACTTTAGCTCGTA & \\
\hline \multirow[t]{2}{*}{$\operatorname{trnH}-p s b \mathrm{~A}$} & $\operatorname{trnH} 1$ & GTTATGCATGAACGTAATGCTC & Shaw et al.[73] \\
\hline & $\operatorname{trnH} 2$ & CGCGCATGGTGGATTCACAATCC & \\
\hline
\end{tabular}

manufacturer's instructions. Three random clones per diploid were chosen to sequence. As there are at least three to five accessions for each allopolyploid in this study, only one random clone for each accession of allopolyploid was picked and sequenced. All clones were sequenced in both directions in Beijing Genomics Institute (BGI, Beijing, China).

\section{Phylogenetic analysis}

Multiple sequences alignments were made using ClustalX [65], with additional manual adjustment. Phylogenetic analyses were performed using Maximum likelihood (ML). Maximum likelihood analyses of the nrITS data, $m a t \mathrm{~K}$ data and trnH-psbA data were performed in PAUP*4.0b10 (Swofford D L, Sinauer Associates, http:// www.sinauer.com). The evolutionary model used for the phylogenetic analyses was determined using ModelTest v3.0 with Akaike information criterion (AIC) [66]. The optimal model were GTR $+\mathrm{G}$ for nrITS data, TVM + G for $m a t \mathrm{~K}$ data, and $\mathrm{K} 81 \mathrm{uf}+\mathrm{G}$ for $t r n \mathrm{H}-p s b \mathrm{~A}$ data. Maximum likelihood heuristic searches were performed with 100 random addition sequence replications and Tree Bisection-Reconnection (TBR) branch swapping algorithm. In order to infer the robustness of clades, bootstrap support (BS) values were calculated with 1000 replications [67].

Table 3 Thermocycling conditions for amplification of genes using the PCR

\begin{tabular}{ll}
\hline Gene & Protocol \\
nrlTS & 1 cycle: $5 \min 95^{\circ} \mathrm{C}$ \\
& 35 cycles: $1 \min 94^{\circ} \mathrm{C}, 1 \min 52^{\circ} \mathrm{C}, 1 \min 72{ }^{\circ} \mathrm{C}$ \\
& 1 cycle: $8 \min 72^{\circ} \mathrm{C}$ \\
matK & 1 cycle: $4 \min 95^{\circ} \mathrm{C}$ \\
& 35 cycles: $1 \min 94^{\circ} \mathrm{C}, 1 \min 50{ }^{\circ} \mathrm{C}, 1.5 \min 72{ }^{\circ} \mathrm{C}$ \\
& 1 cycle: $10 \min 72^{\circ} \mathrm{C}$ \\
trnH-psbA & 1 cycle: $4 \min 95^{\circ} \mathrm{C}$ \\
& 25 cycles: $1 \min 94^{\circ} \mathrm{C}, 1 \min 56{ }^{\circ} \mathrm{C}, 1 \min 72{ }^{\circ} \mathrm{C}$ \\
& 1 cycle: $7 \min 72{ }^{\circ} \mathrm{C}$ \\
\hline
\end{tabular}

\section{Network analysis}

Taking into consideration the potential for reticulation in the evolution of polyploids, phylogenetic network reconstruction method was used to study the relationship between ancestral and derived haplotypes in this study. Because we used known gene genealogies in our simulation studies, the median-joining (MJ) network method was performed [68]. The MJ network method has already been successfully used to study the specific progenitordescendant relationship of polyploidy Triticeae species $[69,70,11]$. The MJ network analysis was generated by the Network 4.6.1.3 program (Fluxus Technology Ltd, Clare, Suffolk, UK). Because the program infers medianjoining networks from non-recombining DNA [71], the GARD recombination detection method within the HyPhy package [72] was used to test for recombination.

\section{Nucleotide diversity estimate}

To assess the gene divergence and genetic relationships in the St genome between polyploids and its diploid progenitor, nucleotide diversity was estimated by Tajima's $\pi$ [73], and Watterson's $\theta[74,75]$. Tajima's $\pi$ quantifies the mean percentage of nucleotide differences among all pairwise comparisons for a set of sequences, while Watterson's $\theta$ is simply an index of the number of segregating (polymorphic) sites. Tests of neutrality including Tajima's and Fu and Li's $D$ statistic were performed as described by Tajima [73], and Fu and Li [76]. Significance of $D$-values was estimated with the simulated distribution of random samples (1000 steps) using a coalescence algorithm assuming neutrality and population equilibrium [77]. These parameters were calculated with DnaSP 4.10.9 [78].

\section{Availability of supporting data}

The data sets supporting the results of this article were deposited in the GenBank (http://www.ncbi.nlm.nih.gov) repository. The phylogenetic trees were deposited in treebase (http://treebase.org) under following URL: http://purl.org/phylo/treebase/phylows/study/TB2:S175 29 ? -access-code $=6966 \mathrm{~b} 2 \mathrm{e} 62 \mathrm{a} 8 \mathrm{abd} 50894460721 \mathrm{ce} 2 \mathrm{f} 4 \mathrm{~b} 7$ \&format=html. The data sets supporting the results of 
this article are included within the article and its additional file.

\section{Additional file}

Additional file 1: Table S1. Species of Elymus sensu lato and the related species used in this study.

\section{Abbreviations}

ML: Maximum likelihood; nrlTS: Nuclear ribosomal internal transcribed spacer; GISH: Genomic in situ hybridization; CTAB: Cetyltrimethyl ammonium bromide; AIC: Akaike information criterion; TBR: Tree bisection-reconnection; BS: Bootstrap support; MJ: Median-joining.

\section{Competing interests}

The authors declare that they have no competing interests.

\section{Authors' contributions}

DZZ designed the study, and wrote the manuscript; DZZ, FX and SLN carried out data analyses; DZZ, ZJ and WY carried out part of experiments; KHY and ZHQ participated in its design and coordination and helped to draft the manuscript. WXL, ZL and DCB collected seed materials; YRW gave the good suggestions in the experiments and manuscript; ZYH planned the study, participated in the design of the experiments, and revised the manuscript. All authors read and approved the final manuscript.

\section{Acknowledgements}

We thank Dr. Norman Ellstrand, University of California Riverside, for copyediting and polishing the style of written English. We also thank three anonymous reviewers for their very useful comments on this manuscript. In addition, the authors are thankful to the National Natural Science Foundation of China (Nos. 30901052, 31200252, 31270243, 31470305), Special Fund for Agro-Scientific Research in the Public Interest of China (No. 201003021), and the Science and Technology Bureau (No. 2060503) and Education Bureau of Sichuan Province, China for the financial support.

\section{Author details}

${ }^{1}$ Triticeae Research Institute, Sichuan Agricultural University, Wenjiang 611130, Chengdu, Sichuan, China. ${ }^{2}$ Key Laboratory of Genetic Resources and Crop Improvement, Ministry of Education, Sichuan Agricultural University, Wenjiang 611130, Chengdu, Sichuan, China. ${ }^{3}$ College of Resources and Environment, Sichuan Agricultural University, Wenjiang 611130, Chengdu, Sichuan, China. ${ }^{4}$ College of Life Science, Sichuan Agricultural University, Yaan 625014Sichuan, China.

Received: 8 December 2014 Accepted: 29 April 2015

Published online: 12 July 2015

\section{References}

1. Soltis DE, Soltis PS, Tate JA. Advances in the study of polyploidy since plant speciation. New Phytol. 2003;161:173-91.

2. Otto SP. The evolutionary consequences of polyploidy. Cell. 2007;131:452-62.

3. Soltis PS, Soltis DE. The role of genetic and genomic attributes in the success of polyploids. Proc Natl Acad Sci U S A. 2000;97:7051-7.

4. Wendel JF. Genome evolution in polyploids. Plant Mol Biol. 2000;42:225-49.

5. Symonds W, Soltis PS, Soltis DE. Dynamics of polyploid formation in Tragopogon (Asteraceae): recurrent formation, gene flow, and population structure. Evolution. 2010;64:1984-2003.

6. Yan C, Sun GL. Multiple origins of allopolyploid wheatgrass Elymus caninus revealed by $R P B 2, P e p C$ and TrnD/T genes. Mol Phylogenet Evol. 2012;64:441-51.

7. Fan X, Sha LN, Dong ZZ, Zhang HQ, Kang HY, Wang Y, et al. Phylogenetic relationships and $Y$ genome origin in Elymus L. sensu lato (Triticeae; Poaceae) based on single-copy nuclear Accl and Pgk1 gene sequences. Mol Phylogenet Evol. 2013;69(3):919-28.

8. Yan C, Sun GL, Sun DF. Distinct origin of the $Y$ and St genome in Elymus species: evidence from the analysis of a large sample of St genome species using two nuclear genes. PLoS One. 2011;6:e26853.

9. Dewey DR. The genomic system of classification as a guide to intergeneric hybridization with the perennial Triticeae. In: Gustafson JP, editor. Gene
Manipulation in Plant Improvement. New York: Plenum Press; 1984. p. 209-80.

10. Lu BR. The genus Elymus L. in Asia. taxonomy and biosystematics with special reference to genomic relationships. In: Wang RRC, Jensen KB, Jaussi C, editors. Proc 2nd Intern Triticeae Symp. Logan, Utah, USA: The Utah State University Press; 1994. p. 219-33.

11. Dong ZZ, Fan X, Sha LN, Zeng J, Wang Y, Chen Q, et al. Phylogeny and molecular evolution of the rbcL gene of St genome in Elymus sensu lato (Poaceae: Triticeae). Biochem Syst Ecol. 2013;50:322-30.

12. Löve Á. Conspectus of the Triticeae. Feddes Repert. 1984;95:425-521.

13. Linnaeus C. Species plantarum. L. Salvius: Stockholm; 1753.

14. Keng YL. Flora illustralis plantarum primarum sinicarum (garmineae). Beijing: Science Press; 1959.

15. Tzvelev NN. Tribe 3. Triticeae dumort. In: Fedorov AA, editor. Poaceae URSS. Leningrad, USSR: Navka Publishing House; 1976. p. 147-81.

16. Barkworth ME. Taxonomy of the Triticeae: a historical perspective. Hereditas. 1992;116:1-14

17. Jensen KB. Cytology and taxonomy of Elymus kengii, E. grandiglumis, E. alatavicus and E. batalinii (Triticeae: Poaceae). Genome. 1990;33:668-73.

18. Chen SL, Zhu GH. Elymus Linn. In: Wu ZY, Raven PH, Hong DY, editors. Flora of China. vol. 22. St. Louis: Science Press, Beijing and Missouri Botanical Garden Press; 2006. p. 400-29.

19. Baum BR, Yen C, Yang JL. Roegneria: its generic limits and justification for its recognition. Canad J Bot. 1991;69(2):282-94.

20. Baum BR, Yen C, Yang JL. Taxonomic separation of Kengyilia (Poaceae: Triticeae) in relation to nearest related Roegneria, Elymus, and Agropyron, based on some morphological characters. Plant Syst Evol. 1995;194:123-32

21. Moench C. Methodus plantas horti botanici et Agri marburgensis a staminum situ describendi, Margburgi Cattorum. 1794.

22. Jensen KB, Wang RC. Cytological and molecular evidence for transferring Elymus coreanus from the genus Elymus to Leymus and molecular evidence for Elymus californicus (Poaceae: Triticeae). Intern J Plant Sci. 1997;158(6):872-7.

23. Zhang HQ, Yang RW, Dou QW, Tsujimoto H, Zhou YH. Genome constitutions of Hystrix patula, H. duthiei ssp. duthiei and H. duthiei ssp. longearistata (Poaceae: Triticeae) revealed by meiotic pairing behavior and genomic in-situ hybridization. Chromosome Res. 2006;14(6):595-604.

24. Church GL. Taxonomic and genetic relationships of eastern North American species of Elymus with setaceous glumes. Rhodora. 1967;69:121-62.

25. Barkworth ME. Taxonomic and nomenclatural comments on the Triticeae in North America. Phytologia. 1997;83:302-11.

26. Yen C, Yang JL. Kengyilia gobicola, a new taxon from west China. Canad J Bot. 1990;68:1894-7.

27. Yen C, Yang JL, Yen Y. Hitoshi Kihara, Áskell Löve and the modern genetic concept of the genera in the tribe Triticeae (Poaceae). Acta Phytotax Sin. 2005;43:82-93.

28. Yen C, Yang JL. Historical review and prospect of taxonomy of tribe Triticeae Dumortier (Poaceae). Breeding Sci. 2009;59:513-8.

29. Zhang $H Q$, Zhou YH. Meiotic analysis of the interspecific and intergeneric hybrids between Hystrix patula Moench and H. duthiei ssp. longearistata, Pseudoroegneria, Elymus, Roegneria, and Psathyrostachys species (Poaceae, Triticeae). Bot J Linn Soc. 2007;153:213-9.

30. Barkworth ME, Cutler DR, Rollo JS, Jacobs SWL, Rashid A. Morphological identification of genomic genera in the Triticeae. Breed Sci. 2009:59:561-70

31. Dou QW, Chen ZG, Liu YA, Tsujimoto H. High frequency of karyotype variation revealed by sequential FISH and GISH in plateau perennial grass forage Elymus nutans. Breeding Sci. 2009;59:651-6.

32. Baum BR, Yang JL, Yen J, Agafonov AV. A taxonomic synopsis of the genus Campeiostachys drobov. J Syst Evol. 2011;49:146-59.

33. Wang RRC, Bothmer RV, Dvorak J, Fedak G, Linde-Laursen I, Muramatsu M. Genome symbols in the Triticeae (Poaceae). In: Wang RRC, Jensen KB, Jaussi C, editors. Proc 2nd Intern Triticeae Symp. Logan, Utah, USA: The Utah State University Press; 1994. p. 29-34.

34. Wang RRC. Genome relationships in the perennial Triticeae based on diploid hybrids and beyond. Hereditas. 1992;116:133-6.

35. Torabinejad J, Mueller RJ. Genome constitution of the Australian hexaploid grass, Elymus scabrus (Poaceae: Triticeae). Genome. 1993;36:147-51.

36. Sang T. Utility of low-copy nuclear gene sequences in plant phylogenetics. Crit Rev Biochem Mol Biol. 2002;37:121-47.

37. Mason-Gamer RJ. Reticulate evolution, introgression, and intertribal gene capture in an allohexaploid grass. Syst Biol. 2004;53:25-37. 
38. Liu QL, Ge S, Tang HB, Zhang XL, Zhu GF, Lu BR. Phylogenetic relationships in Elymus (Poaceae: Triticeae) based on the nuclear ribosomal internal transcribed spacer and chloroplast trnL-F sequences. New Phytol. 2006;170:411-20.

39. Wendel JF, Schnabel A, Seelanan T. An unusual ribosomal DNA sequence from Gossypium gossypioides reveals ancient, cryptic, intergenomic introgression. Mol Phylogenet Evol. 1995;4:298-313.

40. Mahelka V, Kopecký D. Gene capture from across the grass family in the allohexaploid Elymus repens (L.) Gould (Poaceae, Triticeae) as evidenced by ITS, GBSSI, and molecular cytogenetics. Mol Biol Evol. 2010;27:1370-90.

41. Fan X, Liu J, Sha LN, Sun GL, Hu ZQ, Zeng J, et al. Evolutionary pattern of rDNA following polyploidy in Leymus (Triticeae: Poaceae). Mol Phylogenet Evol. 2014;77:296-360.

42. Redinbaugh MG, Jones TA, Zhang Y. Ubiquity of the St chloroplast genome in St-containing Triticeae polyploids. Genome. 2000;43:846-52.

43. Mason-Gamer RJ, Orme NL, Anderson CM. Phylogenetic analysis of North American Elymus and the monogenomic Triticeae (Poaceae) using three chloroplast DNA data sets. Genome. 2002;45:991-1002.

44. Budak H, Shearman CR, Dweikat I. Evolution of Buchloë dactyloides based on cloning and sequencing of matK, rbcL, and cob genes from plastid and mitochondrial genomes. Genome. 2005;48(3):411-6.

45. Luo XM, Tinker NA, Fan X, Zhang HQ, Sha LN, Kang HY, et al. Phylogeny and maternal donor of Kengyilia species (Poaceae: Triticeae) based on three cpDNA (matK, rbcL and trnH-psbA) sequences. Biochem Syst Ecol. 2012;44:61-9.

46. Mason-Gamer RJ. Origin of North America Elymus (Poaceae: Triticeae) allotetraploids based of granule-bound starch synthase gene sequences. Syst Bot. 2001;26:757-8.

47. Fan $X$, Sha LN, Zeng J, Kang HY, Zhang HQ, Wang XL, et al. Evolutionary dynamics of the Pgk1 gene in the polyploid genus Kengyilia (Triticeae: Poaceae) and its diploid relatives. PLoS One. 2012;7, e31122.

48. Sun GL, Ni Y, Daley T. Molecular phylogeny of RPB2 gene reveals multiple origin geographic differentiation of $\mathrm{H}$ genome, and the relationship of the $\mathrm{Y}$ genome to other genomes in Elymus species. Mol Phylogenet Evol. 2008;46:897-907.

49. Wang XL, Fan X, Zeng J, Sha LN, Zhang HQ, Kang HY, et al. Phylogeny and molecular evolution of the DMC1 gene within the StH genome species in Triticeae (Poaceae). Genes Genom. 2012;34:237-44.

50. Drobov VP. Campeiostachys. In: Flora Uzbekistana (Vol 1.). Tashkent: Schroeder RR; 1941. p. 300-1. 540.

51. Yen C, Yang JL, Baum BR. Systematics of Triticeae (Vol.5). Bejing: Agriculture Press; 2013.

52. Agafonov AV, Baum BR, Bailey LG, Agafonova OV. Differentiation in the Elymus dahuricus complex (Poaceae): evidence from grain proteins, DNA, and crossability. Hereditas. 2001;135:277-89.

53. Baum BR, Bailey LG, Johnson DA, Agafonov AV. Molecular diversity of the $5 \mathrm{~S}$ rDNA units in the Elymus dahuricus complex (Poaceae: Triticeae) supports the genomic constitution of St, Y, and $\mathrm{H}$ haplomes. Canad J Bot. 2003;81:1091-103.

54. Savchkova EP, Bailey LG, Baum BR, Agafonov AV. Differentiation of the StHYgenomic Elymus dahuricus complex (Triticeae: Poaceae), revealed with the use of SDS electrophoresis of storage seed proteins and the AFLP analysis. Sibirskiy Ekologicheskiy Zhurnal (Siberian Journal of Ecology). 2003;1:33-42.

55. Agafonov AV, Baum BR, Bailey LG, Agafonova OV, Pluksh ER. Elymus dahuricus complex (Poaceae): Variation, crossability, taxonomy. In: Hernandez P, Moreno MT, Cubero JLA, Martin A, editors. Proceedings of the 4th International Triticeae Symposium: 10-12 September 2001; Cordoba Spain. Cordoba Spain: Viceconcejeria Servicio de Publicationes y Divulgacion (Viceconcejeria Service Publications \& Disclosure); 2002. p. 31-6.

56. Bailey CD, Carr TG, Harris SA, Hughes CE. Characterization of Angiosperm nrDNA polymorphism, paralogy, and pseudogenes. Mol Phylogenet Evol. 2003:29:435-55.

57. Koch M, Al-Shehbaz IA. Molecular systematics of the Chinese Yinshania (Brassicaceae): evidence from plastid trnL intron and nuclear ITS DNA sequence data. Ann Missouri Botanical Garden. 2000;87:246-72.

58. Franzke A, Mummenhoff K. Recent hybrid speciation in Cardamine (Brassicaceae)-conversion of nuclear ribosomal ITS sequences in statu nascendi. Theor Appl Genet. 1999:98:831-4.

59. Popp M, Oxelman B. Inferring the history the polyploid Silene aegaea (Caryophyllaceae) using plastid and homoeologous nuclear DNA sequences. Mol Phylogenet Evol. 2001;20:474-81.
60. Wendel JF, Schnabel A, Seelanan T. Bi-directional interlocus concerted evolution following allopolyploid speciation in cotton (Gossypium). Proc Natl Acad Sci U S A. 1995;92:280-4.

61. Rauscher JT, Doyle JJ, Brown AH. Multiple origins and nrDNA internal transcribed spacer homoeologue evolution in the Glycine tomentella (Leguminosae) allopolyploid complex. Genetics. 2004;166:987-98.

62. Yen C, Yang JL, Baum BR. Systematics of Triticeae (Vol.4). Bejing: Agriculture Press; 2011.

63. Sun GL. Genetic diversity of rbcL gene in Elymus trachycaulus complex and their phylogenetic relationships to several Triticeae species. Genet Resour Crop Evol. 2007;54:1737-46.

64. Doyle JJ, Doyle JL. A rapid DNA isolation procedure for small quantities of fresh leaf tissue. Phytochem Bull. 1987;19:11-5.

65. Thompson JD, Plewniak F, Poch O. A comprehensive comparison of multiple sequence alignment programs. Nucleic Acids Res. 1999;27:2682-90.

66. Posada D, Crandall KA. Modeltest: testing the model of DNA substitution. Bioinformatics. 1998;14:817-8.

67. Felsenstein J. Confidence limits on phylogenies: an approach using the bootstrap. Evolution. 1985;39:783-91.

68. Cassens I, Mardulyn P, Milinkovitch MC. Evaluating intraspecific "network" construction methods using simulated sequence data: do existing algorithms outperform the global maximum parsimony approach? Syst Biol. 2005;54:363-72.

69. Kilian B, Özkan H, Deusch O, Effgen S, Brandolini A, Kohl J, et al. Independent wheat B and $\mathrm{G}$ genome origins in outcrossing Aegilops progenitor haplotypes. Mol Biol Evol. 2007;24:217-27.

70. Fan $X$, Sha LN, Yang RW, Zhang HQ, Kang HY, Zhang L, et al. Phylogeny and evolutionary history of Leymus (Triticeae; Poaceae) based on a single-copy nuclear gene encoding plastid acetyl-CoA carboxylase. BMC Evol Biol. 2009;9:247.

71. Bandelt HJ, Forster $P$, Röhl A. Median-joining networks for inferring intraspecific phylogenies. Mol Phylogenet Evol. 1999;16:37-48.

72. Pond SL, Frost SD, Muse SV. HyPhy: hypothesis testing using phylogenies. Bioinformatics. 2005;21:676-9.

73. Tajima F. Statistical method for testing the neutral mutation of hypothesis by DNA polymorphism. Genetics. 1989;123:585-95.

74. Watterson GA. On the number of segregation sites in genetical models without recombination. Theor Popul Biol. 1975;7:256-76.

75. Wakeley J, Hey J. Estimating ancestral population parameters. Genetics. 1997;145:847-55.

76. Fu YX, Li WH. Statistical tests of neutrality of mutations. Genetics. 1993;133:693-709.

77. Hudson RR. Gene genealogies and the coalescent process. In: Futuyma D, Antonovics J, editors. Oxford Surveys in Evolutionary Biology. New York: Oxford University Press; 1990. p. 1-44.

78. Rozas J, Sánchez-DelBarrio JC, Messeguer X, Rozas R. DNA Sequence Polymorphism, version 4.10.4.; DNAsp4 Computer Software. Barcelona, Spain: Barcelona University; 2005.

\section{Submit your next manuscript to BioMed Central and take full advantage of:}

- Convenient online submission

- Thorough peer review

- No space constraints or color figure charges

- Immediate publication on acceptance

- Inclusion in PubMed, CAS, Scopus and Google Scholar

- Research which is freely available for redistribution 